\title{
Miscigenação versus bipolaridade racial: contradições e conseqüências opressivas do discurso nacional sobre raças
}

\author{
Pedro de Oliveira Filho \\ Universidade Estadual da Paraíba
}

\begin{abstract}
Resumo
Analisamos discursos de brancos acerca do modo bipolar de classificação racial. A abordagem teóricometodológica adotada aqui enfatiza a função e os efeitos do discurso. Freqüentemente, nesses discursos, o modo bipolar é posicionado como racista e o povo brasileiro é apresentado como uma raça mestiça, como um povo sem divisões raciais. São discursos que terminam por obliterar o nosso racismo e a desigualdade entre negros e brancos no Brasil.
\end{abstract}

Palavras-chave: discurso; racismo; classificação racial; miscigenação; psicologia social

\begin{abstract}
Miscegenation against racial bipolarity: contradictions and oppressive effects of national discourse about races. This article analyzes discourses of white people about the bipolar system of racial classification. It focuses on the function and effects of discourse. Often, in these discourses, the bipolar system of racial classification appears as a product of racism and the Brazilian people appear as a mixed race, as a people free of racial separation. They are discourses that hide our racism and the inequality between whites and blacks.
\end{abstract}

Keywords: discourse; racism; racial classification; miscegenation; social psychology

$\mathrm{N}$ o modo de classificação racial dominante na sociedade norte-americana existem somente negros e brancos, não existem categorias intermediárias. Esse modo bipolar de classificação racial está baseado na regra segundo a qual um antepassado negro é suficiente para que um indivíduo seja categorizado como negro. No Brasil, por outro lado, predomina o modo multipolar (ou múltiplo) de classificação racial. Indivíduos com antepassados negros podem ser negros, mas também podem ser mulatos, morenos, pardos, de cor, brancos, etc.

Os brasileiros, em geral, vêem o predomínio do modo multipolar no Brasil como prova de nossa superioridade em relação aos norte-americanos em termos de relações raciais. Fry (1995/1996), um representante desse pensamento no meio acadêmico, argumenta que o modo bipolar norte-americano seria essencialista e mais racista que o modo multipolar.

Por outro lado, diversos autores (d’Adesky, 2001; Munanga, 1999; Skidmore, 1991) e militantes de movimentos afro-brasileiros acentuam as conseqüências políticas negativas advindas do predomínio do modo multipolar no Brasil. Para eles, uma classificação com várias ou mesmo com três categorias raciais seria um artifício ideológico para dividir os não-brancos. Nessa perspectiva, a generalização do uso do modo bipolar de classificação racial no Brasil seria fundamental para tornar mais eficiente a luta dos afro-brasileiros por igualdade social e econômica entre brancos e não-brancos.

Este trabalho, embora não parta do pressuposto de que o predomínio do modo bipolar de classificação racial (ou de qualquer outro modo de classificação racial) seja uma condição necessária para que tenhamos uma sociedade mais igualitária em termos raciais, procura evidenciar que a defesa do modo de classificação racial com múltiplas categorias raciais (categorias sem limites bem definidos) e a apologia da miscigenação que geralmente a acompanha assumem com grande freqüência um caráter ideológico e mistificador nos discursos dos brasileiros. Seu objetivo é analisar as estratégias discursivas utilizadas por brancos brasileiros no combate ao diferencialismo racial que fundamenta o modo bipolar de classificação racial, evidenciar as conseqüências opressivas decorrentes de certos usos do discurso universalista (ou antidiferencialista) associado ao modo multipolar de classificação racial, tal como funciona no Brasil, e evidenciar as contradições, ambigüidades e tensões que caracterizam tal discurso. 


\section{Método}

Utiliza-se neste trabalho a abordagem teóricometodológica de um grupo de pesquisadores da psicologia social (Billig, 1985, 1987, 1991; Potter, 1996; Potter \& Wetherell, 1987; Potter, Wetherell, Gill, \& Edwards, 1990; Wetherell, 1996; Wetherell \& Potter, 1992) que enfatizam a natureza retórica do discurso, sua função e variabilidade.

O tema em questão neste artigo faz parte de uma pesquisa mais ampla, na qual foram entrevistados 60 (sessenta) participantes, fenotipicamente brancos, de diferentes classes sociais e residentes na cidade de Campinas-SP.

Os participantes foram submetidos a um roteiro de entrevista parcialmente estruturado, contendo diversos questionamentos sobre as relações raciais no Brasil. Os discursos analisados aqui são, em sua maioria, respostas ao questionamento acerca da regra segundo a qual um antepassado negro é suficiente para que um indivíduo seja classificado como negro. Todos os participantes cujas falas são analisadas no texto aparecem com nomes fictícios.

\section{Modo bipolar e racismo diferencialista}

Nos discursos dos entrevistados, uma das estratégias mais freqüentes de combate ao modo bipolar é associá-lo, de maneira explícita ou implícita, a um diferencialismo racista de setores não-negros da população:

Lúcio: Não. Normal, porque se eu for afirmar, ah é negro! eu vou tá sendo também...eu vou ser...tá sendo um pouco...preconceituoso. Eu acho que...não tem nada disso, não. Os negros, brancos, tudo é capaz, a mesma coisa, como têm muitas pessoa negra aí no poder, branca também.

João: Não, eu... é normal, branco, negro, tanto faz... pode ser moreno ou pode ser branco. Eu, pra mim não tem a diferença, o pessoal quer colocar, né?, moreno, pode colocar o branco, tanto faz, são todos iguais. Pra mim... É o que eu tô dizendo, pra mim não há diferença nenhuma. Morena, pra mim são todos num nível só. Não tem esse negócio contra... racista. Jamais.

Maciel: Quem pensa assim é o povo que... que... o povo racista, né. Que eu não sei, eu acho... Não tem por que achar, só porque o avô é negro, achar que a pessoa, por mais clara que seja, seja... seja negra também. Sei lá, não existe, não entendo isso.

Tereza: Eu queria ter um antepassado negro (sorrindo). Mas... é... eu não acho... Eu não gosto de caracterizar, se a pessoa é branca, se a pessoa é negra, não. Eu acho assim: independente do tom de pele dela, é pessoa, entendeu?

Geraldo: Eu acho que ser negro, ter um antepassado negro... Eu não vejo essa preocupação, entendeu?, de classificar como negro, como pardo, como mestiço. Acho que não... não faz sentido, não aparenta, a pessoa é uma pessoa, é um indivíduo.
A frase quem escapa de branco é negro é bem característica do modo como esse diferencialismo se apresenta no contexto nacional entre os brancos mais incomodados com a falta de critérios mais claros de classificação racial no Brasil. É a esse racismo diferencialista (geralmente associado pelos brasileiros aos Estados Unidos), racismo que não gosta de ambigüidades nem de misturas, que os entrevistados acima combatem com recursos interpretativos tirados do nosso discurso da democracia racial.

Em algumas falas, o discurso da bipolaridade é posicionado como racista com o argumento segundo o qual tal discurso tem como pressuposto a inferioridade racial do negro. Em outras falas, o modo bipolar de classificação racial é posicionado como racista argumentando-se contra o ato classificatório em si mesmo, contra a necessidade de colocar as pessoas em categorias raciais.

Tereza e Geraldo nos sugerem que, para combater eficientemente o racismo, só precisamos aprender a ver os membros de todos os grupos sociais como indivíduos, como pessoas; só precisamos deixar de pensar no mundo social a partir de categorias como negro, branco, etc. Nesses discursos, como em alguns teóricos da cognição social (Hamilton \& Gifford, 1976; Taylor, Fiske, Etcoff, \& Ruderman, 1978), que tentam explicar a origem dos estereótipos sobre os grupos minoritários a partir de processos cognitivos, o problema parece ser a simplificação e distorção resultantes do processo de categorização através do qual organizamos o mundo social.

Esses discursos pregam claramente o ideário universalista que diversos autores (d'Adesky, 2001; Guimarães, 1999; Munanga, 1999) apontam como um dos fundamentos do nosso racismo, mas ainda falta aqui o uso explícito do discurso da mestiçagem, discurso bem mais eficiente, como veremos, no combate ao diferencialismo presente no modo bipolar.

\section{A mobilização do discurso da mestiçagem}

No Brasil, a questão da mestiçagem entra fortemente na pauta das discussões nacionais na segunda metade do século XIX. Não era sem preocupação que nossa elite intelectual, fortemente influenciada pelas idéias racistas importadas da Europa, discutia a nossa mistura racial e perguntava-se sobre as suas conseqüências para o destino da nacionalidade (Azevedo, 1987; Santos, 2002; Schwarcz, 1995).

Aos poucos, no entanto, começa a surgir um discurso que afirma a positividade da miscigenação. Essa ideologia da miscigenação se consolida no Brasil, como mostra Skidmore (1991), no início do século XX; nesse momento, segundo esse autor, a elite dominante argumentava confiantemente que o Brasil estava livre do racismo, porque estava formando uma única raça por intermédio da miscigenação. Para essa elite, a miscigenação possibilitaria o branqueamento do Brasil.

Com a tese do branqueamento, o caráter positivo da miscigenação passa a ser propagado com o uso dos mais variados argumentos. Num contexto ideológico como esse não nos deve surpreender o fato de que, na fala dos entre- 
vistados desta pesquisa, a idéia de mestiçagem apareça como um recurso interpretativo fundamental no combate ao modo bipolar.

Assim, a categoria mestiço é mobilizada por alguns deles simplesmente como uma categoria que diferencia as pessoas com antepassados negros dos negros e dos brancos, alguém com um antepassado negro não é preto nem branco: é mestiço, misturado, mulato, pardo, etc.

Esse uso da categoria mestiço é muito comum no Brasil, mas também em outras partes do mundo. Mas há um outro modo de mobilização dessa categoria que, se não é exclusivo do Brasil, talvez não se apresente de maneira tão enfática e disseminada em outro lugar do mundo tal como se apresenta aqui. Vejamos alguns exemplos:

Raissa: Olha, eu já me questionei a esse respeito. Ah, eu acho que todos nós, né, os brasileiros, têm... têm um pouquinho de cada..., não é nem raça que eu acho estranho falar raça, né, raça é de bicho, mas eu acho que todos nós temos um pouquinho de negro (...)

Valéria: Eu acho que o... o Brasil ele, a descendência dos brasileiros, é de negros. Eu tenho, você tem, e não adianta você discriminar achar que, não, porque eu sou branco! Mas lá atrás a raiz dele é negra, porque o Brasil foi, né, formado por portugueses e negros. Então... eu tenho, entendeu? E eu acho que é bobagem você falar... Isso é discriminação, né?

Jandira: Eu acho que todos nós temos, né?, um pouquinho da raiz, porque... nós viemos num país de escravidão, né?, e não existe um povo mais misto do que o povo brasileiro, né?, de raça, de tudo, né? A pessoa pode ser a mais, de repente, branca possível e com certeza se ela for vasculhar a história dela vai ter lá uma raiz... raiz negra, né? Porque a nossa história veio disso, né?

Valdemar: Classifico como ela é, brasileira, afinal de contas o Brasil não é uma mistura de... de raças? Ela é bem brasileira (sorrindo).

Abílio: Olha,... eh... no dia a dia, Pedro, eu até ouço, assim, piadas a respeito, entendeu? Mas, eu não consigo imaginar que haja esse... essa manifestação, porque é como eu falei pra você: se nós pegarmos a árvore genealógica de qualquer um, principalmente aqueles que... que... que... são brasileiros há mais tempo, entre aspas, quer dizer: produto de imigrações bem... bem no começo mesmo da história do Brasil, é difícil ter escapado da... da influência da raça. Eu acho que... o negro ele existe na grande parcela. Então, se a maioria possui como é que cê pode... Você normalmente segrega a minoria, né? Eu entendo assim. Quando a norma é ter, então... Não acredito que seja uma manifestação de racismo, no caso, esse tipo de piada, esse tipo de comentário.

Entrevistador: Muita gente... Se bem que isso pode ser visto também de uma... pelo movimento negro é visto de uma maneira positiva. Essa colocação não é... pode ser vista de uma maneira negativa e de uma maneira positiva. Alguém pode dizer... usar esse antepassado pra se afirmar como negro.

Abílio: Olha, eu vou, eu vejo a questão negro e branco... eu vejo da seguinte forma. É claro que, como você colocou na primeira questão, o.... a própria história do negro acabou rotulando e empurrando ou dificultando uma ascensão social. Mas... eh... em termos... em termos de... de... racismo eu acho que a moeda tem dois lados. Da mesma forma como existe o racismo pra com o negro, eu acho... eu acho que também existe o racismo do negro em relação ao branco. Então, como você disse, isso é importante, fortalece o negro? Quer dizer, fortalece por quê? Sabe, eu acho que o objetivo seria... O grande equilíbrio social seria que nem existisse mais o negro nem existisse mais o branco, existisse a mistura de negro e branco. Não só em termos físicos, mas em termos culturais também. Eu acho que é... é... seria esse o caminho, ou seria essa a tendência. Você manter as partes... Não, eu quero fortalecer a raça branca, vamo evitar a mistura social, ou a raça preta. Eu acho que isso sim... essa idéia é desfavorável pra uma paz social. Nesse aspecto.

Nesses discursos não se combate a regra que transforma um indivíduo com algum “sangue negro” em negro simplesmente colocando esse indivíduo em uma terceira categoria diferente das categorias negro e branco. Não se argumenta simplesmente que esse indivíduo é mestiço. Argumenta-se que todos os brasileiros, ou a maioria absoluta dos brasileiros, são mestiços. O brasileiro tem o negro e o branco dentro de si. O brasileiro não é negro, nem branco ou é negro e branco simultaneamente.

De acordo com esses discursos, falar no Brasil em modos de categorização cujas categorias sejam rigidamente diferenciadas não faz qualquer sentido. No Brasil, nos dizem esses discursos, mesmo os brasileiros mais brancos têm algum antepassado negro: a descendência dos brasileiros é negra; todos os brasileiros têm algum antepassado negro, mesmo aqueles que se acham brancos "puros"; todos nós temos um "pouquinho da raiz".

A categoria mestiço não aparece nesses discursos para diferenciar, para criar uma categoria intermediária entre o negro e o branco; aparece como uma categoria que ora diminui as diferenças entre negros e brancos (um branco com algum “sangue negro” tem um pouco de negro dentro de si, é um “pouco negro”) ora elimina, dissolve, essas categorias (todo brasileiro é mestiço). Os brasileiros são posicionados como um grupo social homogêneo, sem divisões, como uma única raça.

Em algumas falas, o modo bipolar de classificação racial é posicionado como uma manifestação de racismo fora do lugar, levando-se em conta as características nacionais. Se todos são "brasileiros”, mestiços, se todos, mesmo os mais "brancos”, têm um pouco de "sangue negro", ou da cultura negra, o racismo só pode ser um sentimento de pessoas que desconhecem a própria origem. O discurso de Abílio é exemplar, nesse sentido. Para ele, no Brasil é pouco provável que alguém tenha "escapado da influência da raça”. Portanto, se 
a "maioria possui” algum antepassado negro, o racismo no Brasil é algo sem sentido, absurdo.

Em Abílio, quanto mais mestiçagem mais paz e harmonia social. Com a eliminação total das características somáticas e culturais de negros e brancos por intermédio da mistura racial, teremos o "grande equilíbrio social”. O discurso de Abílio poderia ter sido escrito por um dos pais fundadores do discurso da mestiçagem. Como afirma Munanga (1999): “A mestiçagem, como articulada no pensamento brasileiro entre o fim do século XIX e meados deste século (o século XX), seja na sua forma biológica (miscigenação), seja na sua forma cultural (sincretismo cultural), desembocaria numa sociedade unirracial e unicultural” (p. 90).

\section{A aparência e a origem}

É bem conhecida a constatação de Nogueira (1988) segundo a qual no Brasil uma pessoa é classificada em termos de cor ou de raça principalmente a partir de sua aparência, de sua "marca”, diferentemente dos Estados Unidos que classificam a partir da origem ou do "sangue". Abaixo podemos observar a aparência sendo mobilizada para combater o discurso da origem ou do "sangue".

Leonardo: Não, isso não tem nada a ver. Negro é uma questão de... de aparência física mesmo, é uma questão física, não tem nada a ver.

Joaquim: Não! O negro, ele tem a pele negra.

Entrevistador: Tem a pele negra.

Joaquim: Entendeu?

Entrevistador: Tá jóia.

Joaquim: Não é que tem o sangue de negro. E o sangue dele é vermelho igual dos outros.

Selma: Ah, não sei falar. Não é... negro... Negro pra mim, negro, é aquele de tez bem escura mesmo, (palavra incompreensível) africanos ou... Existem... miscigenação, né?, os misturados, assim,... Não acho que... mesma... É o preconceito da raça, né, se a pessoa tem um traço de negro ele também vai ser discriminado (...)

Luciana: Ah, eu acho... eu acho que não. Eu acho que não deve ser classificado. Também não teria importância se fosse, né?, porque...vai isso de cada um, né? Cada um pensa uma coisa, né? Eu acho que não, eu acho que... que se torna tudo igual , tudo uma coisa, mas têm pessoas que acha, né?, que... quem tem descendência de negro, porque ele têm sangue de negro, porque ele... Que que tem a gente ter sangue de negro? Tem nada demais. É um sangue como qualquer outro, né?

Os entrevistados procuram desracializar a racializada idéia de "sangue"; procuram negar que o sangue transmita alguma essência racial misteriosa. Não se pode negar o caráter desmistificador do ataque a esse velho conceito racista. Mas, em alguns desses discursos, os predicados físicos exigidos para que alguém possa ser considerado um negro, "pele negra”, “tez bem escura”, produzem uma redução evidente na quantidade de indivíduos que poderiam ser classificados como negros no Brasil.

Tais discursos podem seduzir os não-brancos sem a "tez bem escura” por lhes dizerem implicitamente que eles não são tratados da maneira discriminatória como os negros são tratados no Brasil. Mas, como bem sabe um porteiro de Campinas conhecido do entrevistador, grande parte dos descendentes de africanos no Brasil não recebe de fato o mesmo tratamento dispensado aos brancos. O referido porteiro, sem pele escura, com traços africanos discretos, contou para o autor desta pesquisa que, certa vez, em um de seus primeiros dias de trabalho num edifício residencial (edifício que já tinha um negro indiscutível, de "tez bem escura”, como um de seus porteiros), ouviu de uma descuidada moradora do referido edifício, que estava na porta do elevador conversando com outro morador: "Só contratam preto pra essa portaria".

Os denominados brancos na sociedade brasileira nunca são indiferentes a marcas físicas indicadoras de ascendência africana, por mais discretas que sejam. Os mulatos podem até ascender socialmente com mais facilidade do que os negros, mas a condição de descendente de negros daqueles nunca é esquecida, e pode ser usada a qualquer momento contra eles, como forma de colocá-los em "seu lugar".

\section{Contradições, inconsistências, ambigüidades}

Os discursos sobre os mais diferentes temas variam tanto no interior de um mesmo grupo social quanto em diferentes intervenções discursivas de um mesmo indivíduo. Nesses discursos não vamos encontrar somente consistência, encontraremos também inconsistência, ambigüidade, contradição.

Tal variabilidade ocorre, em primeiro lugar, porque a linguagem é usada para uma variedade de funções. Os nossos discursos são flexíveis e constroem as mais variadas versões da realidade, não são simplesmente reflexos da realidade, são versões da realidade que procuram atingir determinados objetivos (Potter \& Wetherell, 1987).

Mas é preciso reconhecer, como faz Billig, que a variabilidade nos discursos ocorre também porque, quando argumentam, as pessoas reproduzem em seus discursos as diversas concepções que estão em conflito no interior da sociedade, do "senso comum”. A variabilidade não é somente uma conseqüência de "considerações estratégicas", é conseqüência também da própria natureza do senso comum e dos seus temas em conflito (Billig, 1991).

Observações feitas por Pinto (1953/1998) nos anos 50 do século passado, na cidade do Rio de Janeiro, ilustram bem a atualização do conflito entre diferentes valores sociais num nível subjetivo. Pinto (1953/1998) observa nos discursos de diferentes sujeitos postulados contraditórios, como o seguinte, que, segundo ele, expressariam simultaneamente o desejo de mudança e o desejo de conservação das relações sociais existentes: "O negro deve ser igual ao branco, pois todos somos filhos de Deus; mas, é uma falta de respeito essas liberdades que essa negrada anda tomando hoje em dia.” (p. 162). 
Nos discursos dos entrevistados de nossa pesquisa, a variabilidade discursiva se apresenta em relação aos mais diferentes temas. Em relação ao tema abordado neste artigo, gostaríamos de destacar os elementos diferencialistas e antidiferencialistas que se misturam, nos discursos de alguns deles, de maneira contraditória e inconsistente.

Vejamos primeiramente algumas falas de Túlio, o único entrevistado do grupo cujo discurso diferencialista, em certo momento, aproxima-se, em alguns aspectos, de um diferencialismo racista bem comum na Europa atual. O momento no qual seu discurso mais se aproxima desse diferencialismo racista é quando responde sobre o que pensa de supostos racistas brancos paulistanos que andariam pregando a violência contra a população negra:

Túlio: Ah cara, isso aí é sacanagem. É ignorância deles, entendeu? Não tem nem o que falar, cara, é ignorância deles porque aquele que não consegue ver uma outra pessoa como semelhante... desculpe eu falar, é ignorante. O cara não quer ver o sujeito... Tudo bem, ele tem uma cor diferente, isso a gente não pode negar. Tem o olho puxado se for japonês, tal, essas coisas, não pode negar. Mas, afinal, ele tem cinco membros, ele tem... ele tem a cabeça, ele tem os membros, ele tem o tórax, ele é igual a gente, entendeu cara? Ele só desenvolveu numa região diferente, lá na dele. Eu acho... Isso aí cara é tudo culpa da mistura, né? A verdade é essa porque... Eu não sou... eu não sou racista mas eu sou a favor de cada um no seu lugar, por quê? Justamente pra isso: preservar a cultura, você... ter o seu direito. Se... se os negros nunca tivessem se misturado, por exemplo,... Claro, não foi culpa deles, nós que fomos lá e invadimos o país deles. Mas se eles nunca tivessem se misturado, eles estariam lá na cultura deles, os japoneses também tariam lá na cultura deles. Cada um na sua, e não ia tá hoje essa guerra. (trecho incompreensível), eu sou de... eu sou democrata o outro é republicano tentando fazer a mesma coisa que é administrar o país. E não vai a lugar nenhum porque cada um quer uma coisa. E assim fica a sociedade hoje cara. Várias culturas num lugar que nem o Brasil, por exemplo, onde tá tudo miscigenado cara (...)

Deve-se notar primeiramente a condenação inequívoca da violência racial nesse discurso, algo que não é descartado como recurso extremo por um diferencialismo racial ansioso por preservar a pureza de grupos raciais ou culturais. Não obstante essas características, as semelhanças desse discurso com o diferencialismo racista são evidentes. Como no racismo diferencialista europeu (para uma análise desse racismo, ver: Miles, 1989; Wieviorka, 1992), Túlio evita falar sobre raças, ou em inferioridade e superioridade racial. São as culturas que aparecem como definindo a essência de cada grupo, são elas que devem ser preservadas.

Seu discurso faz claramente a apologia de uma sociedade com grupos culturais separados, embora iguais.

Em outros momentos, o discurso de Túlio segue coerente com esse diferencialismo. Em alguns momentos, de maneira bem próxima ao diferencialismo anti-racista dos movimentos negros, Túlio sugere que o fortalecimento de uma identi- dade coletiva entre os negros é um passo necessário para por fim a uma situação de desigualdade.

Diante de todas essas demonstrações de diferencialismo, poderíamos esperar um discurso favorável ao modo bipolar de classificação racial. O modo bipolar, afinal, marca bem as diferenças, não deixa lugar para ambigüidades, reforça as identidades grupais. Mas quando perguntamos a Túlio sobre o que ele pensa da afirmação segundo a qual um antepassado negro transforma alguém em negro, segue-se o seguinte diálogo:

Túlio: Não penso nada. O meu sócio, inclusive, o pai dele é filho de negro. Se... se pensar dessa forma... Aliás, eu não vejo nada porque aqui cara isso aí é muito da criação também porque, aqui no bairro, aqui a gente sempre tem convivência com negro, aqui é normal, entendeu?

Entrevistador: Mas você diria que uma pessoa que tem um antepassado negro é negra?

Túlio: Não, não, não, não, não. Não digo que é negra, cara. Oh, negro pra mim é o que aparenta ser na pele, e mesmo assim, cara, tem uns que a gente não pode distinguir, né?, porque é mestiço. Mas... vamos dizer assim que... Não eu não vejo isso, vai. Coloca... Se o cara é filho de negro eu não vejo como negro. Como um negro mesmo, que todo mundo vê assim. Mesmo porque a gente não... não faz diferença, né? Acho que começa por aí.

Como entender essa inconsistência? Pode-se supor que a rejeição do modo bipolar na última fala de Túlio é, em parte, uma tentativa de mostrar-se desvinculado de uma posição racista. O diferencialismo proposto por Túlio na sua primeira fala é bastante popular entre os ideólogos do atual racismo europeu, fato que o torna passível de ser interpretado como um diferencialismo racista. O próprio Túlio indica essa vulnerabilidade quando diz na referida fala que não é "racista". No entanto, esse diferencialismo também pode ser posicionado como culturalista, como um diferencialismo que só se preocupa com a pureza e preservação das culturas, não das raças. Já o diferencialismo que Túlio rejeita na sua última fala é um diferencialismo explicitamente racializado, um discurso indubitavelmente racista para os brasileiros.

Não estamos afirmando que o diferencialismo em todas as suas formas seja aquilo no que ele acredita "de verdade" e que a recusa do diferencialismo em sua forma racial seja uma decorrência somente de uma estratégia de auto-apresentação positiva. Embora o universalismo seja dominante no Brasil, diferencialismo e universalismo em suas diversas formas convivem de maneira conflituosa, inconsistente e ambígua na sociedade brasileira. A inconsistência encontrada nos discursos de Túlio pode ser vista como a atualização desse conflito num nível subjetivo.

Nos trechos retirados da entrevista de Sandra, abaixo, podemos encontrar mais um exemplo desse conflito. Nesses trechos, podemos encontrar, em um momento, um discurso que critica a tendência nacional para evitar a bipolaridade e, em outro momento (de maneira contraditória), um discurso simpático ao modo multipolar de classificação. 
Sandra: Eu acho que aprender história de uma maneira geral é interessante. Acho que... sem... sem querer dar tanta ênfase (palavra incompreensível), acho que é válido. Se nós tivemos... muita... muita história sobre a... a... a população branca européia, que são os imigrantes (palavra incompreensível) aqui, né?, eu acho que tem que ter conhecimento... Mais uma vez: evitando a discriminação..., esse negócio de bairrismo, de bandeira, eu não gosto muito disso; eu acho que isso acaba partindo pra... prum lado ruim que é a violência, depois, né? Quer dizer: um contra o outro. Eu acho que tem que haver uma integração. E acho que quando perguntam pro negro, qual é a sua cor? Tem que falar: sou negro!, num tem que falar: sou moreno, sou queimadinho, sou não-sei-o-quê, que é o que se escuta aqui, né? Sou meio escuro. Então é: sou negro e acabou!, né? E o mulato: sou negro!, porque ele é negro mesmo, né? Então... acontece que ele... ele próprio tem vergonha de dizer o que ele é. $\mathrm{O}$ branco tem... tem... fica com... cheio de dedos também pra falar que tem um amigo negro, quer dizer: parece que todo mundo tem um pouco de vergonha pra falar a coisa, não sei o quê que acontece.

Sandra: Bom, eu não... não sou uma expert em parte de genética; eu acho que tem genes recessivos, dominantes; eu não sei o quê que é recessivo e dominante em alguém que tem um (palavra incompreensível)... um antepassado negro. Não sei o quê que é. Pra mim, cor é cor. Acho que se divide pelo... pelo... pelo exterior, não é?, mais ou menos.

Entrevistador: A senhora classificaria pela aparência, então? Sandra: Num primeiro momento, sim, que é pra mim a classificação mais óbvia, né? Quer dizer: a pele, a tez e tudo mais. Se ele se considera negro porque teve um avô negro e os outros três avós italianos, aí é um problema dele, não é verdade? Se é três a um e ele acha que um ganha... aí é o critério dele. Agora, geneticamente, cientificamente, eu não sei como... é... classificar, mas me parece que você tem que ter uma certa proporção. Se você tem dois negros e dois brancos, ele é meio a meio, né? Se você tem um negro com três brancos, ele é mais branco do que negro. Isso é um problema de... de... genético, que também é matemático, né? Então (trecho incompreensível) problema matemático.

No primeiro trecho, Sandra está respondendo sobre o que pensa de um currículo escolar com disciplinas que enfatizem a história e a cultura da África. Tal currículo é apresentado pelo entrevistador como uma proposta de setores da população negra. Sandra procura se mostrar simpática ao diferencialismo implícito nessa proposta. Para ela, o conhecimento das origens étnicas e o orgulho dessas origens aparecem como algo positivo. Por isso o negro e também o mulato devem dizer claramente que são negros. Nada de moreno e queimadinho.

No segundo trecho, Sandra está rejeitando o modo bipolar de classificação racial. Para combatê-lo Sandra mobiliza dois critérios de classificação, a aparência e um critério genético que leve em conta a quantidade de antepassados negros e de antepassados brancos do indivíduo. Esses critérios aparecem em seu discurso como mais racionais, mais próximos do bom senso, do que o critério origem tal como usado no modo bipolar.

Esse trecho é ao mesmo tempo coerente e contraditório em relação ao primeiro. É contraditório porque nele o modo bipolar é apresentado como contrário ao bom senso, enquanto no primeiro ele é apresentado quase como um fato da natureza: o mulato deve se classificar como negro "porque ele é negro mesmo”. É coerente em relação ao primeiro trecho porque no primeiro texto se encontram também elementos anti-diferencialistas. De fato, Sandra diz no primeiro trecho dos dois supracitados que devemos falar da história e da cultura africanas, mas sem muita "ênfase", pois isso pode resultar em violência, conflito. No discurso de Sandra, o multicuturalismo diferencialista e politicamente correto que circula nas classes médias educadas se mistura com o nosso velho discurso anti-diferencialista produzindo inconsistências, contradições e ambigüidades.

\section{Anti-diferencialismo e desigualdade}

Por tudo o que foi visto até aqui, fica evidente que não devemos conceber os modos multipolar e bipolar de classificação como estruturas cognitivas inflexíveis pelas quais os entrevistados veriam a realidade social. Quando alguns deles dizem que alguém com um antepassado negro é mulato, não devemos entender tal fala simplesmente como a expressão de uma estrutura cognitiva que só consegue se expressar em termos de três ou mais categorias raciais. Com a rejeição do modo bipolar, os entrevistados estão menos expressando uma determinada estrutura cognitiva do que defendendo um conjunto de idéias que gostam de ver associadas à idéia de Brasil: a harmonia entre as raças, a nãoseparação entre as raças, a indiferenciação racial, a ausência de preconceito racial, etc.

Entretanto, a tendência para a rejeição pública do modo bipolar não significa sua ausência dos nossos discursos e comportamentos cotidianos, mesmo dos discursos e comportamentos das pessoas que o rejeitam com mais veemência na arena pública. Em contraposição a esse conjunto de discursos que falam de uma sociedade com várias categorias raciais sem limites rigidamente delimitados ou com uma única categoria racial, os brasileiros, se encontra outro conjunto de discursos produtores de bipolaridade que emergem em situações específicas.

Fry (1995/1996), um ardoroso defensor do modo múltiplo usado no Brasil, reconhece que, no Brasil, uma mesma pessoa pode, dependendo da situação, usar o modo múltiplo ou o bipolar. De fato, é muito comum no Brasil que uma pessoa seja, numa situação de conflito, qualificada de negra (ou preta) por pessoas que em outras situações o qualificam de moreno, mulato, branco. Tal fato indica que as mais variadas cores usadas para classificar as pessoas que aparecem nos discursos dos brasileiros (e que indicariam a nossa incapacidade para dividir nossa realidade social somente em termos de duas raças, a negra e a branca, ou mesmo nossa incapacidade para pensar em termos de raças) não são tão desracializadas quanto gostamos de pensar. 
No Brasil, com grande freqüência, argumentos a favor do modo multipolar, da mestiçagem ou de uma raça brasileira, atuam concretamente contra os interesses da população negra, pois freqüentemente são argumentos que, de maneira consciente ou inconsciente, procuram esconder a profunda desigualdade que caracteriza as relações entre brancos e nãobrancos; procuram esconder que, de fato, os dois grupos são diferenciados em termos de riqueza, poder e prestígio. O termo racismo universalista é perfeitamente adequado para denominar o nosso racismo. Esse é um dos termos utilizados por Taguieff (1987) para diferenciar um racismo tolerante em relação à miscigenação racial e cultural, um racismo que afirma uma humanidade comum aos diferentes grupos raciais (mas que, paradoxalmente, promove a desigualdade racial), de um racismo diferencialista que tem horror à miscigenação e que, para preservar as diferenças, pode até apelar para a eliminação física de outros grupos.

Mas o discurso da mestiçagem não é necessariamente um discurso opressivo, um discurso cujo objetivo é produzir ou perpetuar a desigualdade. Um termo do repertório antidiferencialista, raça brasileira, por exemplo, pode seguir diferentes direções argumentativas (Wetherell \& Potter, 1992), pode ser usado para os mais diversos fins, opressivos e nãoopressivos. Do mesmo modo, um termo do repertório diferencialista, direito à diferença, por exemplo, pode ser usado (e freqüentemente o é) tanto para fins libertários quanto para fins opressivos, tanto por militantes do anti-racismo quanto por racistas de extrema direita.

Por isso é necessário um olhar atento e crítico direcionado para a mobilização de diferentes discursos sobre relações raciais e para suas possíveis conseqüências. Quando se faz isso em relação ao discurso da mestiçagem, torna-se evidente que, no Brasil, o elogio da mestiçagem tem reforçado, com grande frequiência, o nosso mito da democracia racial, mito que, como afirma Munanga, (1999), impede, com sua exaltação da harmonia entre todos os grupos raciais, a consciência, entre os não-brancos, dos sutis mecanismos de exclusão que os atingem.

\section{Referências}

Azevedo, C. M. M. de (1987). Onda negra medo branco: o negro no imaginário das elites-século XIX. Rio de Janeiro: Paz e Terra.
Billig, M. (1985). Prejudice, categorization, and particularization: from a perceptual to a rhetorical approach. European Journal of Social Psychology, 15, 79-103.

Billig, M. (1987). Arguing and thinking: a rhetorical approach to social psychology. Cambridge: Cambridge University Press.

Billig, M. (1991). Ideology and opinions. Londres: Sage.

d' Adesky, J. (2001). Pluralismo étnico e multiculturalismo: racismos e antiracismos no Brasil. Rio de Janeiro: Pallas.

Fry, P. (1995/1996). O que a Cinderela negra tem a dizer sobre a 'política racial' no Brasil. Revista USP, 28, 122-135.

Guimarães, A. S. A. (1999). Racismo e anti-racismo no Brasil. São Paulo: Editora 34.

Hamilton, D. L., \& Gifford, R. K. (1976). Illusory correlations in interpersonal perception: a cognitive basis of stereotypic judgments. Journal of Experimental Social Psychology, 12, 392-407.

Miles, R. (1989). Racism. Londres: Routledge.

Munanga, K. (1999). Rediscutindo a mestiçagem no Brasil: identidade nacional versus identidade negra. Petrópolis: Vozes.

Nogueira, O. (1998). Preconceito de marca: as relações raciais em Itapetininga, São Paulo: Edusp.

Pinto, L. A. C. (1998). O negro no Rio de Janeiro: relações de raça numa sociedade em mudança ( $2^{\underline{a}}$ ed.). Rio de Janeiro: Editora da UFRJ. (texto original publicado em 1953)

Potter, J. (1996). Attitudes, social representations and discursive psychology. In M. Wetherell (Org.), Identities, groups and social issues (pp.119-173). Londres: Sage \& Open University.

Potter, J., \& Wetherell, M. (1987). Discourse and social psychology: beyond attitudes and behaviour. Londres: Sage.

Potter, J., Wetherell , M., Gill, M., \& Edwards, D. (1990). Discourse: noun, verb or social practice? Philosophical Psychology, 3, 205-217.

Santos, G. A. dos (2002). A invenção do ser negro: um percurso das idéias que naturalizaram a inferioridade dos negros. São Paulo: Educ/Pallas.

Schwarcz, L. M. (1995). O espetáculo das raças: cientistas, instituições e questão racial no Brasil (1870-1930). São Paulo: Companhia das letras.

Skidmore, T. E. (1991). Fato e mito: descobrindo um problema racial no Brasil. Cadernos de Pesquisa, 79, 5-16.

Taguieff, P-A. (1987). La force du préjugé: essai sur le racism et ses doubles. Paris: Gallimard.

Taylor, S. E., Fiske, S. T., Etcoff, N.L., \& Ruderman, A. (1978). Categorical and contextual bases of person memory and stereotyping. Journal of Personality and Social Psychology, 36, 778-793.

Wetherell, M. (1996).Group conflict and the social psychology of racism. In M. Wetherell (Org.), Identities, groups and social issues (pp.175-238). Londres: Sage \& Open University.

Wetherell, M., \& Potter, J. (1992). Mapping the language of racism: discourse and the legitimation of exploitation. Hemel Hempstead: Harvester Wheatsheaf.

Wieviorka, M. (1992). El espacio del racismo. Barcelona: Paidós.

Pedro de Oliveira Filho, doutor em Psicologia Social pela Pontifícia Universidade Católica de São Paulo, é professor na Faculdade de Psicologia da Universidade Estadual da Paraíba. Endereço para correspondência: Rua Rodrigues Alves, 1040, apto. 201, Bela Vista; Campina Grande, PB; CEP 58101-290. Tel: (83) 3421089. E-mail: pedroofilho@ig.com.br 